\title{
AN UNUSUAL PRESENTATION OF A HUGE BREAST TUMOUR IN AN ELDERLY FEMALE: A CASE REPORT
}

Prasenjit Bhattacharya ${ }^{1}$, Sudipta Chatterjee ${ }^{2}$, Subir Kumar Majumdar³, Himadri Sekhar Kar ${ }^{4}$, Amalesh Barman $^{5}$

\section{HOW TO CITE THIS ARTICLE:}

Prasenjit Bhattacharya, Sudipta Chatterjee, Subir Kumar Majumdar, Himadri Sekhar Kar, Amalesh Barman. "An Unusual Presentation of a Huge Breast Tumour in an Elderly Female: A Case Report". Journal of Evolution of Medical and Dental Sciences 2014; Vol. 3, Issue 28, July 14; Page: 7837-7839, DOI: 10.14260/jemds/2014/2981

ABSTRACT: Pleomorphic breast carcinoma is a rare variety of breast carcinoma, with a highly aggresive behaviour and poor prognosis, which usually presents after 50 years of age. Our case presented in a very similar way as phyllodes' tumour of breast (even the FNAC report also suggested it as a case of phyllodes' tumour). But postoperative histopathological report clearly revealed it as a case of this rare entity of pleomorphic carcinoma of breast.

KEYWORDS: Breast Tumour in elderly lady, Phyllodes' tumour, Pleomorphic Carcinoma.

INTRODUCTION: Pleomorphic breast carcinoma is a poorly described entity whose phenotype is not well recognised. It is a high grade variant of carcinoma breast (NOS) which usually presents after 50 years of age. ${ }^{1}$ Here we are presenting such a case of a 70 years female.

CASE REPORT: A 70 years old lady presented with a huge mass in the right breast for 2 months without any H/O nipple discharge, systemic or axillary lymph node metastasis. O/E it is a mass with $15 \mathrm{~cm}$ diameter, globular in shape, occupying the entire breast, mildly tender, firm, smooth, with overlying stretched out excoriated skin at some places. No remarkable nipple changes found. No palpable axillary lymphadenopathy found. On FNAC, it was diagnosed as a Phyllodes' tumour.

Patient undergone simple mastectomy. Recovery was uneventful. Histopathological examination showed it as a case of pleomorphic ductal carcinoma. Receptor status evaluation was beyond the scope of our institution. After discharge, the patient attended our OPD for follow up only once. So, further follow up could not be done.

DISCUSSION: Pleomorphic carcinoma of breast is a rare entity. It is diagnosed when $\geq 50 \%$ of the tumour shows pleomorphic cell population ( $>6$ fold variation in nuclear size). ${ }^{1}$ Mean age of presentation is 53 (51-55) years and mean size is $54 \mathrm{~mm}$. Most are clinically diagnosed as a palpable mass and in minority, in screening mammography, this tumour often fails to show classic characteristics of breast carcinoma e.g. lack of calcification and sometimes shows features of benign breast disease or malignant phyllodes' tumour.

USG shows it is a low echo mass with distinct circumscription and intracystic features within the tumours. T2-weighted MRI shows a homogeneous hyperintense cystic mass and contrast enhancement in irregular portions of the tumour walls. Adjacent DCIS or transition to a classic ductal carcinoma can be seen. Histologically, most the tumours are Grade III. Some may have giant cells and they have high $(>20 \% / \mathrm{HPF})$ mitotic rate with abnormal mitosis. Spindle cell component is found in $40 \%$ cases and can make upto $25 \%$ of the total tumour mass. $50 \%$ cases have positive lymph node status in axilla. Metastasis most commonly to the liver followed by lung, pleura and bone. 
Most of the tumours are aneuploid and have a high S-phase fraction $(>10 \%)$. All cases are ER negative and mostly PR, Bcl-2 and Her-2/neu negative. ${ }^{[2,3]}$ Although invasive lobular carcinoma is less aggresive than it's ductal counterpart but pleomorphic lobular carcinoma is very aggresive and usually Grade II or III.[4,5] They have greater vascular invasion and more multifocality.[4] Loss of Heterozygosity and lack of E-Cadherin are characteristic of this. ${ }^{[3,6,7]}$ In most cases modified radical mastectomy and in minority, breast conservation surgery is undertaken. A 5-year disease free survival is $40 \%$ although about $40 \%$ of women with pleomorphic breast cancer may succumb to the disease in 2-3 years. ${ }^{[2,8]}$ Absence of spindle cell component and tumor size of less than $5 \mathrm{~cm}$ at the time of diagnosis has positive effect on survival.

\section{REFERENCES:}

1. Silver SA, Tavassoli FA. Pleomorphic carcinoma of the breast: clinicopathological analysis of 26 cases of an unusual high-grade phenotype of ductal carcinoma. Histopathology 2000 Jun; 36(6):505-14.

2. Kymionis GD, Dimitrakakis CE, Konstadoulakis MM et al. Can expression of apoptosis genes, bcl-2 and bax, predict survival and responsiveness to chemotherapy in nodenegative breast cancer patients? J Surg Res 99;2001:161-168

3. Wahed A, Connelly J, Reese T. E-cadherin expression in pleomorphic lobular carcinoma: an aid to differentiation from ductal carcinoma. Ann DiagnCytopathol 6;2002:349-51

4. Gil Deza E, Japaze H, Garcia Gerardi C, Diaz C, Gercovich N, Morgenfeld E, Rivarola E, Russo M, Frahm I, Gercovich FG. Lobular invasive pleomorphic breast cancer (BC) should be isolated from the classic type. Journal of Clinical Oncology, ASCO Annual Meeting Proceedings Part I, 2007 June 20 (Supplement); Vol 25, No. 18S: 17024

5. Dabbs DJ, Grenko RT, Silverman JF. Fine needle aspiration cytology of pleomorphic lobular carcinoma of the breast. ActaCytol 1994; 38:923-6.

6. Takeichi M. Cadherin cell adhesion receptors as a morphogenetic regulator, Science, 1991 Mar 22; Vol. 25, No. 5000: 1451-1455.

7. Palacios J, Sarrio D, Garcia-Macias MC, Bryant B, Sobel M, Merino MJ. Frequent E-cadherin Gene Inactivation by Loss of Heterozygosity in Pleomorphic Lobular Carcinoma of the Breast. Mod Pathol 2003; 16(7):674-678

8. Hardy Gh. Mendelian Proportions in a mixed population. American Association for the Advancement of Science, Science, New Series, 1908 Jul; 28(706):49-50. 
Figure 1: Sections from breast lump shows proliferation of pleomorphic and bizarre tumor giant cells comprising of $70 \%$ of tumour cells in the background of poorly differentiated adenocarcinoma. itotic figure is 22 per HPF. Tumour necrosis is prominent. Actually it qualifies grade III carcinoma (Nottingham modification of the Bloom - Richardson system of grading). Here in the picture (40X) there are two abnormal mitotic figures (marked by arrow). Even in the 10X magnification abnormal mitosis is obvious.

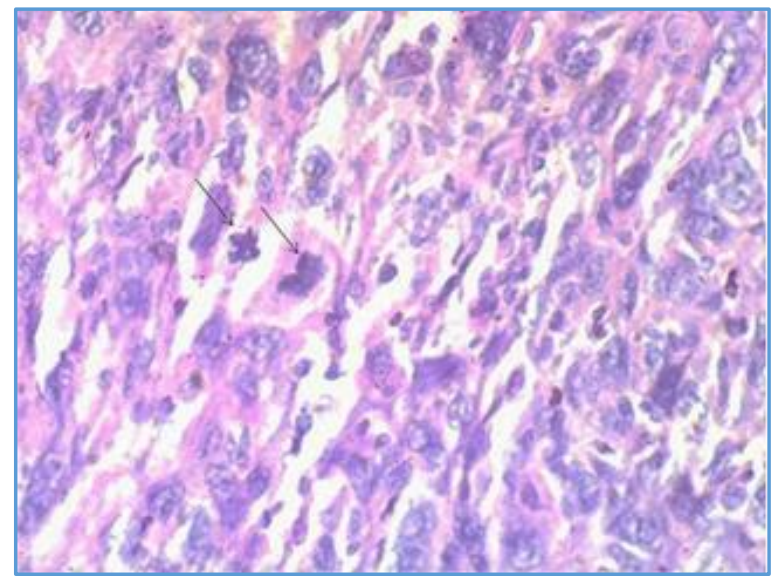

Figure 1

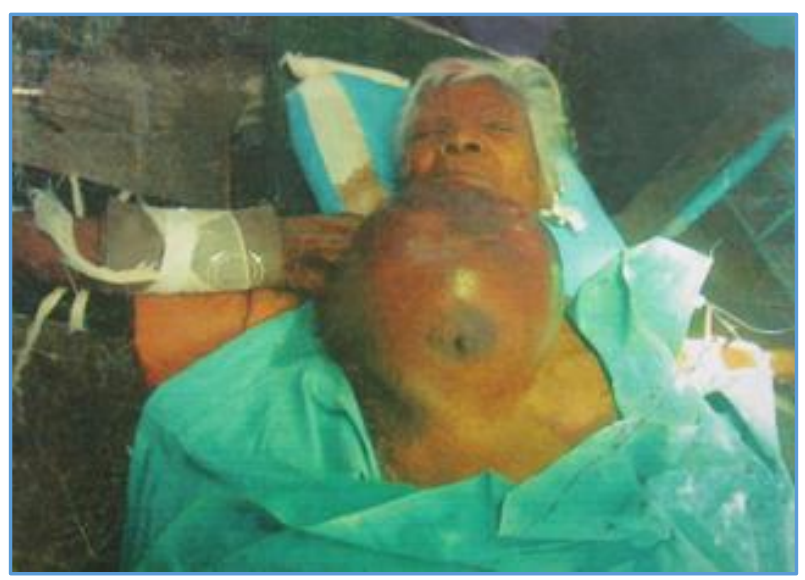

Figure 2

\section{AUTHORS:}

1. Prasenjit Bhattacharya

2. Sudipta Chatterjee

3. Subir Kumar Majumdar

4. Himadri Sekhar Kar

5. Amalesh Barman

\section{PARTICULARS OF CONTRIBUTORS:}

1. RMO-Cum-Clinical Tutor, Department of General Surgery, Midnapore Medical College \& Hospital.

2. RMO-Cum-Clinical Tutor, Department of General Surgery, Midnapore Medical College \& Hospital.

3. Associate Professor, Department of General Surgery, Midnapore Medical College \& Hospital.

4. Assistant Professor, Department of General Surgery, Midnapore Medical College \& Hospital.
5. Associate Professor, Department of General Surgery, Midnapore Medical College \& Hospital.

\section{NAME ADDRESS EMAIL ID OF THE} CORRESPONDING AUTHOR:

Sudipta Chatterjee,

Razabazar,

P. O. Midnapore-721101,

District-Paschim Medinipur,

West Bengal.

Email: sudiptac77@gmail.com

Date of Submission: 20/06/2014.

Date of Peer Review: 21/06/2014.

Date of Acceptance: 30/06/2014.

Date of Publishing: 12/07/2014. 